surface treatments of the sheets and by the amount of insulation beneath them, four galvanised iron sheets, measuring $4 \mathrm{ft} .3 \mathrm{in}$. square, were supported off the ground and exposed out of doors at the Building Research Station. One sheet was left plain, another was formed into a shallow tank and filled to a depth of $1 \mathrm{in}$. with water ; the two remaining sheets were whitewashed on the upper surface and one was provided with $7 \mathrm{in}$. of cork insulation underneath.

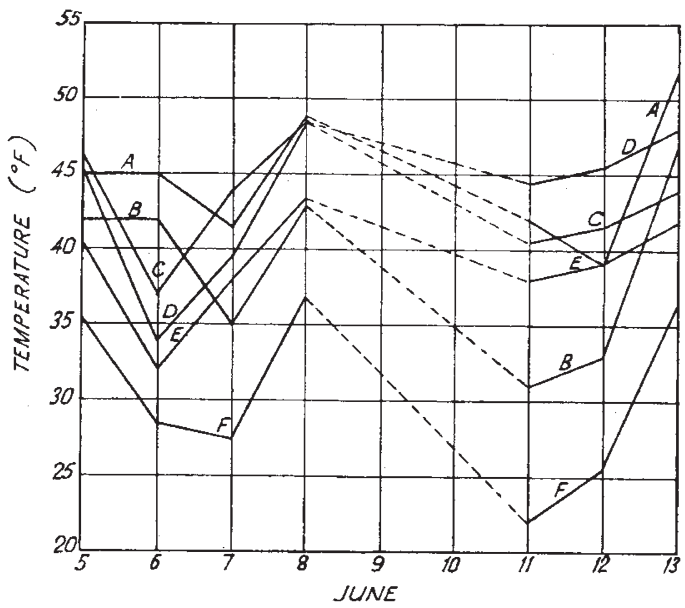
A. IN STEVENSON SCREEN
IRON SHEET UNTREATEO.
B. ON GRASS
E. IRON SHEET, WHITEWASHED.
F. IRON SHEET, WHITEWASHED.
C. IRON SHEET, WITH WATER (WITH $7 "$ CORK BENEATH).

FIG. 1. Minimum temperatures.

Each sheet was provided with a thermocouple by means of which its temperature was recorded. The minimum temperatures recorded on a number of nights in June are shown in Fig. 1. It will be seen that the specimen which was whitewashed on top, to reflect the sun's heat by day and to radiate heat by night, and was heavily insulated beneath with cork, became appreciably colder than any of the other specimens, the lowest temperature recorded being $22^{\circ} \mathrm{F}, 2^{\circ} \mathrm{F}$. below the screen minimum for the night.
The next step was to experiment on a larger scale with an actual roof, to find how much dew could be collected. For this purpose a section of a corrugated iron roof, $18 \mathrm{ft} .7 \mathrm{in}$. long by $11 \mathrm{ft}$. wide and having a pitch of $7 \frac{1}{2}^{\circ}$, was provided with separate drainage. The roof was insulated underneath with two sheets of aluminium-faced asbestos paper, spaced 1 in. apart, the equivalent of about 1 in. of cork, and was whitewashed on top. The temperature of the iron sheets was recorded by means of a thermocouple.

Measurements were made on this roof on suitable clear nights from July to September, but the results were disappointing. Dew could be collected on nights most favourable for the loss of heat by radiation, but suitable nights were by no means frequent, and, even then, the amount of dew collected was small. A typical record is given below.

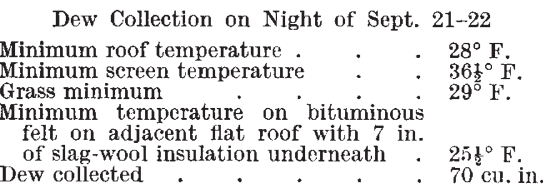

The quart of water which is obtained on a night when the sky is propitious is a mere dribble compared with the 10 gallons which the same roof collects during $1 / 10$ inch of rainfall, and it is obvious that, as an auxiliary water-supply during drought, the collection of dew in this way cannot be seriously considered. Storage for rain water is more economical to instal, more reliable and altogether more practicable.

From the experiments described above, it may also be inferred that the action of 'dew-ponds' cannot be ascribed to the ordinary deposition of dew. This corroborates the findings of E. A. Martin ${ }^{1}$, who as a result of an extensive study, decided that the ponds depend for their replenishment upon mists rather than dew and that the term 'dew-pond' is a misnomer. According to Martin, the wcrd 'dew-pond' does not appear to have been used prior to 1813 ("The Shorter Oxford English Dictionary" gives the date 1877) and, since then, although some ponds have borne that name, others have been known as 'cloud-ponds', 'mist-ponds' or 'fog-ponds'.

1 E. A. Martin, "Dew-Ponds". T. Werner Laurie, Lt,d., London, 1911.

\title{
Sylvicultural Research in Nigeria
}

GINCE the appointment of two sylviculturists for research in Nigeria in 1928, a remarkable amount of good work has been undertaken in connexion with the rain and moist deciduous forests in the south-western provinces. In the Oxford Forestry Memoirs, No. 18 (Oxford, The Clarendon Press; 1934), Mr. W. D. MacGrogor, one of the sylviculturists, publishes an account of his work in a brochure entitled "Sylviculturo of the Mixed Deciduous Forests of Nigeria, with Special Reference to the South-Western Provinces".

The mixed deciduous forest type in West Africa is an important concomitant of the forest flora, coming between the true deciduous and the true evergreen forest types. Botanically it includes high forest treos of both types, but differs from the deciduous forest in containing evergreen under canopies, and from the evergreen or rain forest in containing top canopies of deciduous trees.

From the forester's point of view, the mixed deciduous forest type is nearer to the deciduous than to the rain forest type. It is in reality a climatic formation in which deciduous trees attain their optimum development. In its most humid form, the mixed deciduous merges imperceptibly into the rain forest type. It requires a rainfall averaging $50-70$ inches per annum.

Of the numerous natural orders of this forest type, Sterculiaceae, Leguminosae, Moraceae and Combretaceae are the most important. The two magnificent trees Triplochiton scleroxylon and Chlorophora excelsa have the greatest range in distribution.

With the evergreen forests to the south and the deciduous forests to the north, the mixed deciduous 
forests form an almost continuous belt of varying width running parallel to the coast. They are said to hold great timber wealth of large dimensions. They have not been exploited, however, to anything like the extent of the rain forests owing to their geographical position, which places them outside the zone of streams and rivers suitable for floating timber.

The object of Mr. MacGregor's memoir is to record all the experimental and research work in connexion with the sylviculture of the mixed deciduous forest type upon which he has been specially engaged; or on which other officers have obtained some experience of, for example, plantation work. In the latter work, fuel plantations have formed an important branch. Large areas of indigenous species have been planted at Akilla, Ondo Circle. At Mamu and Olokemeji teak has been successfully grown-but almost, until recently, at the expense of good local indigenous species. Latterly, however, research work in the nursery and plantation has been devoted to the study of the requirements of indigenous species with the view of replacing exotic species when possible.

It is a curious anomaly that here in the West African tropical forests, with a plethora of magnificent timber trees of which almost the only one known, during the past century at least, was mahogany, the first commencements of forest plantation work on a scientific basis should have been made with teak in several colonies to the neglect of some of the, admittedly little-known, indigenous species. The research work with the latter undertaken by $\mathrm{Mr}$. MacGregor and ably depicted in this memoir proves that West Africa has timbers which will probably, in the future, be able to hold their own on any timber market in the world.

In addition to the nursery and experimental plantation work undertaken with indigenous species, sylvicultural experimental work in connexion with both artificial and natural regeneration has been commenced with considerable success.

Chapters are devoted to the description of the sylvicultural characters of a number of species, indigenous and exotic, and some excellent deseriptions of seedlings. Finally, there is a report on the soils at Olokemeji by Mr. H. C. Doyne, senior agricultural chemist, and Mr. W. A. Watson, agricultural chemist, Ibadan.

Although perhaps it is too early to accept the mass of detail recorded in this important memoir as actually proved, without further check, yet Nigeria may be complimented on the methods upon which the work has been carried out.

\section{The Broadcasting Wave-Lengths of Europe}

$7 \mathrm{HE}$ plan for allocating the wave-lengths of the broadcasting stations in Europe published in 1934, and known as the Lucerne plan, is getting more and more difficult to work. The trouble arises mainly from the fact that the full range of frequencies available for the carrier waves is 1,350 kilocycles per second, and in order to prevent serious overlapping, each station requires a width of about 10 kilocycles per sec. In order to secure agreement between the various nations concerned, it was necessary to allocate 133 channels to 170 working stations, so that some had to work at the same frequency, care being taken to give these frequencies to small stations at a great distance from one another.

Unfortunately, little attention had been given to limiting the power of large broadcasting stations, and so there are now thirteen in Europe which work at 100 kilowatts or above, eighteen with powers not less than $50 \mathrm{kw}$. and twenty with powers not less than $20 \mathrm{kw}$. Many of these stations are transmitting through the same zone of darkness, and it follows that the spectra of the waves radiated by powerful stations in contiguous channels will overlap. The overlapping sidebands of these unwanted stations produce serious interference.

In a paper on broadcast transmission read to the Institution of Electrical Engineers on May 1 by $\mathrm{Mr}$. P. P. Eckersley, it is pointed out that at the present time the designer of a receiver capable of reproducing distant as well as local programmes is forced to cut off the upper audio frequencies of modulation, and this deleteriously affects the quality of the reproduction. The ordinary commercial receiver sold to-day to the public cuts off the audio frequencies above 3,500 cycles per second.

The only way to get over this difficulty is to change radio technique. It is improbable that European nations will agree to limit either the existing power or the number of their working stations. But if it were possible to modify transmitters so that the spectra of the waves radiated contained the carrier wave and only one set of sidebands, spectrum overlap could be minimised and in some cases entirely eliminated. If a frequency band of 2,000 cycles per second could be added to the ordinary breadth, a great improvement would result. The introduction of high-fidelity broadcasting would undoubtedly stimulate the industry of radio broadcasting.

Mr. Eckersley has recently been to the United States and has inspected the apparatus developed by Wired Radio Inc. for use in connexion with their high-frequency broadcasting system. He found that several of the methods he recommended were similar to their methods, and that a very high quality of reproduction was achieved.

\section{University and Educational Intelligence}

CAMBRIDGE.-The sixth course of Scott Lectures will be given by Prof. G. Hevesy in the Cavendish Laboratory at 4.30 p.m. on May 13,15 and 17 . The subject of the course will be "The Terrestrial and Cosmic Abundance of the Elements".

An election to the Isaac Newton Studentship will be held in the Michaelmas Term 1935. These studentships are for the furtherance of advanced study and research in astronomy and physical optics and are open to those members of the University who have obtained a degree in the University and were less than twenty-five years of age on January 1, 1935. Candidates are invited to send in their applications to the Vice-Chancellor between October 8 and 14 , 1935. The emolument of the student will be $£ 250$ per annum.

Edinburgh.-Mrs. Stewart Hall has given $£ 15,000$ for the endowment of a lectureship in the pathology of the diseases of children.

On the recommendation of the Joint Committee of the University Court and the managers of the Royal Infirmary, Dr. A. E. Barclay, lecturer in medical radiology, University of Cambridge, has been appointed lecturer in radiology in the University, on his appointment as radiologist to the Royal Infirmary from May 1, 1935. 